Article

\title{
Liposome-Mediated Delivery of MERS Antigen Induces Potent Humoral and Cell-Mediated Immune Response in Mice
}

\author{
Masood Alam Khan ${ }^{1, *(\mathbb{D})}$, Ajamaluddin Malik ${ }^{2}$, Mohammad A. Alzohairy ${ }^{3}$, Abdulmohsen M. Alruwetei ${ }^{3}{ }^{(0)}$ \\ Bader Y. Alhatlani ${ }^{4}{ }^{(}$, Osamah Al Rugaie ${ }^{5}\left(\mathbb{C}\right.$ and Arif Khan ${ }^{1}{ }^{1}$ \\ 1 Department of Basic Health Sciences, College of Applied Medical Sciences, Qassim University, \\ Buraydah 51452, Saudi Arabia; 4140@qu.edu.sa \\ 2 Department of Biochemistry, College of Science, King Saud University, Riyadh 11451, Saudi Arabia; \\ amalik@ksu.edu.sa \\ 3 Department of Medical Laboratories, College of Applied Medical Sciences, Qassim University, \\ Buraydah 51452, Saudi Arabia; zhiery@qu.edu.sa (M.A.A.); roietaie@qu.edu.sa (A.M.A.) \\ 4 Department of Applied Medical Sciences, Applied College in Unayzah, Qassim University, \\ Unayzah 51911, Saudi Arabia; balhatlani@qu.edu.sa \\ 5 Department of Basic Medical Sciences, College of Medicine and Medical Sciences, Qassim University, \\ Unayzah 51911, Saudi Arabia; o.alrugaie@qu.edu.sa \\ * Correspondence: a_khan@qu.edu.sa; Tel.: +966-507059437; Fax: +966-63801628
}

check for

updates

Citation: Khan, M.A.; Malik, A.; Alzohairy, M.A.; Alruwetei, A.M.; Alhatlani, B.Y.; Rugaie, O.A.; Khan, A. Liposome-Mediated Delivery of MERS Antigen Induces Potent Humoral and Cell-Mediated Immune Response in Mice. Molecules 2022, 27, 403. https://doi.org/10.3390/ molecules27020403

Academic Editor: Mohammad Zaki Ahmad

Received: 29 November 2021

Accepted: 6 January 2022

Published: 9 January 2022

Publisher's Note: MDPI stays neutral with regard to jurisdictional claims in published maps and institutional affiliations.

Copyright: (C) 2022 by the authors. Licensee MDPI, Basel, Switzerland. This article is an open access article distributed under the terms and conditions of the Creative Commons Attribution (CC BY) license (https:// creativecommons.org/licenses/by/ $4.0 /)$.

\begin{abstract}
The advancements in the field of nanotechnology have provided a great platform for the development of effective antiviral vaccines. Liposome-mediated delivery of antigens has been shown to induce the antigen-specific stimulation of the humoral and cell-mediated immune responses. Here, we prepared dried, reconstituted vesicles (DRVs) from DPPC liposomes and used them as the vaccine carrier system for the Middle East respiratory syndrome coronavirus papain-like protease (DRVs-MERS-CoV PLpro). MERS-CoV PLpro emulsified in the Incomplete Freund's Adjuvant (IFAMERS-CoV PLpro) was used as a control. Immunization of mice with DRVs-MERS-CoV PLpro did not induce any notable toxicity, as revealed by the levels of the serum alanine transaminase (ALT), aspartate transaminase (AST), blood urea nitrogen (BUN) and lactate dehydrogenase (LDH) in the blood of immunized mice. Immunization with DRVs-MERS-CoV PLpro induced greater antigenspecific antibody titer and switching of IgG1 isotyping to IgG2a as compared to immunization with IFA-MERS-CoV PLpro. Moreover, splenocytes from mice immunized with DRVs-MERS-CoV PLpro exhibited greater proliferation in response to antigen stimulation. Moreover, splenocytes from DRVsMERS-CoV PLpro-immunized mice secreted significantly higher IFN- $\gamma$ as compared to splenocytes from IFA-MERS-CoV PLpro mice. In summary, DRVs-MERS-CoV PLpro may prove to be an effective prophylactic formulation to prevent MERS-CoV infection.
\end{abstract}

Keywords: liposome; vaccine delivery; MERS-CoV; antiviral immunity

\section{Introduction}

In the last two decades, the appearance of severe acute respiratory syndrome coronavirus-1 (SARS-CoV-1), the Middle East respiratory syndrome coronavirus (MERS-CoV), and severe acute respiratory syndrome coronavirus-2 (SARS-CoV-2) has posed a serious threat to the existence of human population across the world [1]. The World Health Organization (WHO) has included MERS-CoV in the priority list of the diseases [2]. The first case of MERS-CoV infection was detected in Saudi Arabia and the kingdom covered almost 80\% of the total MERs-CoV infection cases [3]. Those taking care of camels are suggested to be an easy target of MERS-CoV [4]. Furthermore, healthcare workers are considered another major target of MERS-CoV infections [5]. Those with, e.g., diabetes, kidney failure, chronic lung disease, and immunosuppression are purported to show a high mortality rate due to acute respiratory failure, cardiovascular collapse, and renal dysfunction [6,7]. 
A successful vaccine against MERS-CoV infection should be able to activate neutralizing antibodies and antigen-specific T-cell responses. Importantly, it should be safe and should not induce toxic manifestations in immunized individuals. Currently, there is no vaccine available to prevent MERS-CoV infection in human beings. Earlier, recombinant MERS-CoV and viral-vector-based vaccines have been shown to induce both humoral and cell-mediated immune responses. Furthermore, they were also effective in reducing the MERS-CoV infection in animal models [8]. Coleman et al. reported that purified MERS-CoV spike protein-bearing nanoparticles induced a higher antibody titer [9]. A MERS spike protein synthetic DNA vaccine has been demonstrated to induce protective immunity against MERS-CoV infection in non-human primates [10]. The immunization of MERS-CoV receptor-binding domain (RBD) protein in combination with the adjuvants, Montanide ISA51 or Poly IC, induced superior titer of long-term neutralizing antibodies [11]. A liposome-encapsulated complex of MERS-CoV S protein and CpG-DNA induced the generation of monoclonal antibodies that specifically targeted the $S$ protein of MERSCoV [12].

Recent advances in the field of nanotechnology-based vaccine delivery systems have provided great promises in the development of effective vaccines that can induce strong immune responses. Certain nanoparticles such as liposomes, microspheres, and chitosan-nanoparticles have demonstrated potent vaccine carriers and immune-adjuvant actions [13,14]. A vaccine is considered effective in protecting against viral infections if it has the ability to induce antigen-specific antibody and cell-mediated immune responses. The advantage with liposomes is that they can be loaded with a variety of antigens in order to deliver them to the antigen-presenting cells (APCs). The use of neutralizing antibodies, interferons, and the inhibitors of viral proteases are considered important therapeutic strategies in the treatment of MERS-CoV infection $[15,16]$. Taking into account the graveness and possible future consequences of the MERS-CoV infections, it is very important to find effective prophylactic measures to prevent a future possible pandemic of MERS-CoV. MERS-CoV papain-like protease (MERS-CoV PLpro) is a cysteine protease that plays an important role in viral maturation [17]. MERS-CoV PLpro deubiquitinates interferon regulatory factor 3 (IRF3) and suppresses the production of interferon $\beta$ (IFN- $\beta$ ) [18]. It is considered a very important drug target in order to develop effective therapeutic agents [19]. In the present work, we developed a liposomal formulation of MERS-CoV-PL and used it as a vaccine formulation to immunize the mice. The outcomes showed that liposome-encapsulated MERS-PLpro induced stronger antigen-specific antibody and $\mathrm{T}$ cell responses in mice.

\section{Materials and Methods}

\subsection{Materials}

1,2-Dipalmitoyl-Sn-glycero-3-phosphocholine (DPPC) and cholesterol (Chol) were purchased from the Avanti Polar Lipids (Alabaster, AL, USA). Sandwich ELISA colorimetric assay kits for the determination of IFN- $\gamma$ (ab100689) and IL-4 (ab100710) were purchased from Abcam (Cambridge, UK). A CellTiter $96^{\circledR}$ non-radioactive cell proliferation colorimetric assay kit was purchased from the Promega Corporation (Madison, WI, USA).

\subsection{Mice}

Female Swiss mice of the age of 10 weeks were used in the immunization experiments. Experimental procedures were approved by the animal ethics committee of the College of Applied Medical Sciences, Qassim University, Buraydah, Saudi Arabia.

\subsection{Expression and Purification of MERS-CoV Papain-like Protease (PLpro)}

A papain-like protease (PLpro) of MERS-CoV was expressed and purified by our collaborator Dr Ajamaludin Malik in his laboratory at the Department of Biochemistry, King Saud University, Riyadh, Saudi Arabia [20]. MERS-CoV PLpro cloned in the pET28a vector under strong 77 promoter was transformed into E. coli BL21(DE3) pLysSstrain. For biomass preparation, a liter-scale expression experiment was set up and $1 \%$ of the overnight 
culture was transferred in the fresh $1 \mathrm{~L} \mathrm{LB}$ medium containing $200 \mu \mathrm{g} / \mathrm{mL}$ of ampicillin and incubated at $37^{\circ} \mathrm{C}$ in a shaking incubator. When the culture reached the mid-log phase of growth, it was induced using $0.4 \mathrm{mM}$ isopropyl- $\beta{ }^{-} \mathrm{D}^{-}$-thiogalactopyranoside (IPTG). The culture was further incubated overnight at $20^{\circ} \mathrm{C}$ and $135 \mathrm{rpm}$. The cells were harvested by centrifugation at $6000 \mathrm{rpm}$ at a temperature of $4{ }^{\circ} \mathrm{C}$ for $15 \mathrm{~min}$.

The cell pellet was re-suspended in the lysis buffer (consists of lysozyme, EDTA, NP-40, and benzonase) and subjected to mild physical force (sonication at low amplitude for short periods) to gently extract soluble proteins from E. coli. The lysate was cleared by centrifugation at high speed (13,000 rpm, $30 \mathrm{~min})$ and filtered through a 0.45 -micron filter. Subsequently, the cleared lysate was passed through an equilibrated $5 \mathrm{~mL}$ Ni-NTA column, and the bound proteins were eluted using an imidazole gradient at a fixed flow rate using the AKTA FPLC system. The purity of the eluted proteins was analyzed by SDSPAGE. Relatively enriched fractions were pooled and further purified using size exclusion chromatography. The pooled fraction from Ni-NTA was loaded on the Sephadex 75 column equilibrated with $20 \mathrm{mM}$ Tris-HCl buffer ( $\mathrm{pH}$ 8.5) containing $100 \mathrm{mM} \mathrm{NaCl}$ and $1 \mathrm{mM}$ DTT at a fixed flow rate of $1 \mathrm{~mL} / \mathrm{min}$. Again, the purity of eluted fractions was analyzed on SDS-PAGE. The highly purified fractions of MERS-CoV PLpro were pooled and stored at $-80{ }^{\circ} \mathrm{C}$. Before immunization, contamination of LPS in the protein sample was ruled out by silver staining of the SDS-PAGE that showed only the required protein band.

\subsection{Preparation and Characterization of $D R V S$}

Liposomes were prepared using DPPC and cholesterol as described earlier [21]. DPPC and cholesterol were dissolved in a mixture of chloroform/methanol (1:1 vol/vol). The solvents were slowly evaporated in a rotary evaporator to form a transparent thin lipid film. The film was hydrated by using phosphate-buffered saline (PBS) containing MERS-CoV PL pro antigen. The mixture was frozen and lyophilized to obtain the dried, reconstituted vesicles (DRVs). The DRVs were rehydrated and the final volume was reconstituted by adding PBS. The mixture was centrifuged at $10,000 \mathrm{rpm}$ for $15 \mathrm{~min}$ at $4{ }^{\circ} \mathrm{C}$ in the cooling centrifuge and the amount of free antigen present in the supernatant was estimated. The percentage of encapsulation efficiency ( $\%$ EE) was calculated by the following formula:

$$
1-\mathrm{A}_{\text {Free antigen }} / \mathrm{A}_{\text {Total antigen }}
$$

where $A_{\text {Free antigen }}$ is the amount of antigen present in the supernatant; $A_{\text {Total antigen }}$ is the amount of total antigen initially added.

The size and shape of the DRVs were determined by transmission electron microscopy (TEM), whereas the polydispersity index (PDI) and zeta potential were revealed by the Malvern Nano Zeta Sizer (Malvern Instruments, Southborough, MA, USA), using the dynamic light scattering (DLS) technique as previously described [22].

\subsection{Immunization of Mice}

Each mouse was immunized through the subcutaneous route with a dose of $10 \mu \mathrm{g}$ $(0.2 \mathrm{~mL})$ of MERS-CoV PLpro emulsified in the Incomplete Freund's Adjuvant (IFA-MERSCoV PLpro) or MERS-CoV PLpro encapsulated in DRVs (DRVs-MERS-CoV PLpro) as described earlier [23]. Furthermore, each mouse was injected with two booster doses of IFA-MERS-CoV PLpro or DRVs-MERS-CoV PLpro on days 14 and 21. Mice were divided into the following groups and each group contained 10 mice:

1. Saline

2. Sham liposomes

3. Incomplete Freund's Adjuvant (IFA)-MERS-CoV PLpro (IFA-MERS-CoV PLpro)

4. Dried and reconstituted vesicles (DRVs)-MERS-CoV PLpro (DRVs-MERS-CoV PLpro). 


\subsection{Assessment of the Safety of Vaccine Formulations}

Blood was taken from mice of each group on day 5 after the final booster dose of immunization. In order to determine the safety of immunization, we analyzed the levels of the serum alanine transaminase (ALT), aspartate transaminase (AST), blood urea nitrogen (BUN), and lactate dehydrogenase (LDH) in the blood of control and immunized mice $[23,24]$.

\subsection{Determination of Antigen-Specific Antibody Titer and Ratio of IgG2a/IgG1 Isotypes in Immunized Mice}

Blood was taken from the mice of each group on day 5 after the final booster dose of immunization and the serum was separated by centrifugation at $1500 \mathrm{rpm}$. The titer of antigen-specific antibodies was quantified by ELISA as previously described [25]. The impact of the immunization with IFA-MERS-CoV PLpro or DRVs-MERS-CoV PLpro was determined on the generation of antigen reactive IgG1 and IgG2a isotypes in the sera of the immunized mice by ELISA.

\subsection{Antigen-Specific Lymphocyte Proliferation Assay}

Antigen-specific proliferation of lymphocytes was performed in the splenocytes using CellTiter 96 non-radioactive cell proliferation assay kit from Promega Corp. (Madison, WI, USA) following the instructions of the manufacturer. Splenocytes $\left(1 \times 10^{6}\right.$ cells $/$ well $)$ from the mice in various groups were collected into a 96-well sterile cell culture plate, stimulated, and incubated with MERS-CoV PLpro $(10 \mu \mathrm{g} / \mathrm{mL})$ at $37^{\circ} \mathrm{C}$. After $72 \mathrm{~h}$, the plates were centrifuged at $1500 \mathrm{rpm}$ for $5 \mathrm{~min}$ and the supernatant was collected. A solution of [3-(4,5-dimethylthi-azol-2-yl)-5-(3-carboxymethoxyphenyl)-2-(4-sulfophenyl)$2 \mathrm{H}$-tetrazolium + phenazine methosulfate was added to the splenocytes and incubated at $37^{\circ} \mathrm{C}$. After $4 \mathrm{~h}$, the absorbance was measured at $570 \mathrm{~nm}$ using a microplate reader.

\subsection{Determination of IFN- $\gamma$ and $I L-4$}

On day 5 post-final booster dose, three mice were sacrificed from each group and their spleens were excised to prepare a single-cell suspension by using the gentleMACs ${ }^{\mathrm{TM}}$ Dissociator (Miltenyi Biotec, Bergisch Gladbach, Germany). The splenocytes $\left(1 \times 10^{6}\right)$ were re-suspended in RPMI-1640 medium supplemented with 10\% FBS, $100 \mathrm{U} / \mathrm{mL}$ penicillin, $100 \mu \mathrm{g} / \mathrm{mL}$ streptomycin and $2 \mathrm{mM}$ L-glutamine [21]. The splenocytes were stimulated with MERS-CoV PLpro $(10 \mu \mathrm{g} / \mathrm{mL})$ and incubated for $48 \mathrm{~h}$ at $37^{\circ} \mathrm{C}$. The supernatant was collected and the amounts of IFN- $\gamma$ and IL- 4 were analyzed by ELISA [21].

\subsection{Statistical Analysis}

The data were analyzed by one-way analysis of variance (ANOVA) followed by a Turkey post-test using GraphPad Prism software, version 6.0 (La Jolla, CA, USA). A value of $p<0.05$ was considered statistically significant.

\section{Results}

\subsection{Characterization of DRVS}

The PDI value of the DRVs was found to be 0.464 , whereas the zeta potential was found to be $-4.18 \mathrm{mV}$. A PDI value between 0 and 1 suggests greater stability of the DRVs. The size of liposomes was found to be in the range of 40-220 nm (Figure 1A,B). The entrapment efficiency of the antigen in DRVs was found to be $51.2 \%$. 
A

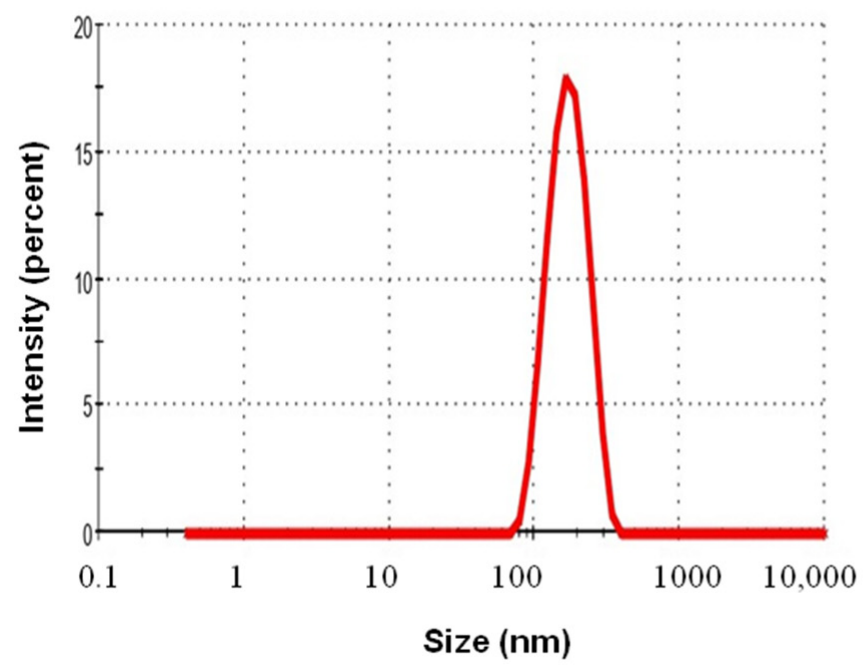

B

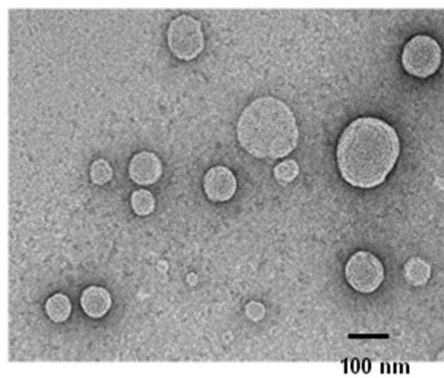

Figure 1. Characterization of DRVs. (A) Size of liposomes by DLS technique; (B) shape and size of liposomes by TEM.

3.2. Immunization with DRVs-MERS-CoV PLpro Did Not Induce Any Significant Toxicity in Mice

The toxicity of vaccine formulation in the mice was assessed by analyzing the levels of AST, ALT, BUN, and LDH in the blood of immunized mice. Mice immunized with DRVs-MERS-CoV PLpro or IFA-MERS-CoV PLpro did not show any considerable elevation in the levels of AST, ALT, BUN, and LDH in the blood (Figure 2). The level of AST was found to be $21.33 \pm 4.933 \mathrm{IU} / \mathrm{L}$ in the saline-injected mice, whereas the AST level increased to $34 \pm 2 \mathrm{IU} / \mathrm{L}$ in mice immunized with IFA-MERS-CoV PLpro $(p<0.05)$ (Figure 2A). However, mice immunized with DRVs-MERS-CoV PLpro had an AST level of $25 \pm 4.5 \mathrm{IU} / \mathrm{L}(p>0.05)$. The ALT level was found to be $18 \pm 5 \mathrm{IU} / \mathrm{L}$ in saline-injected mice. Mice immunized with IFA-MERS-CoV PLpro showed an ALT level of $28.67 \pm 3 \mathrm{IU} / \mathrm{L}$, whereas those immunized with DRVs-MERS-CoV PLpro had an ALT level of $24 \pm 5.7 \mathrm{IU} / \mathrm{L}$ (Figure 2B). The effect of immunization on renal toxicity was assessed by determining the level of BUN. The BUN levels were found to be $20.67 \pm 5$ and $25 \pm 6 \mathrm{mg} / \mathrm{dL}$ in the blood of mice injected with saline and sham-lip (Figure 2C). Nevertheless, the BUN level was significantly increased to $31 \pm 7.4 \mathrm{mg} / \mathrm{dL}$ in mice immunized with IFA-MERS-CoV PLpro $(p<0.05)$. Importantly, mice immunized with DRVs-MERS-CoV PLpro had a BUN level of $27.33 \pm 7.5 \mathrm{mg} / \mathrm{dL}(p>0.05)$. Similarly, the LDH level in mice injected with saline was $1143 \pm 107 \mathrm{U} / \mathrm{L}$ that was increased to $1331 \pm 106 \mathrm{U} / \mathrm{L}$ in mice immunized with IFA-MERSCoV PLpro (Figure 2D). Mice immunized with DRVs-MERS-CoV PLpro had an LDH level of $1242 \pm 198 \mathrm{U} / \mathrm{L}$. 
A

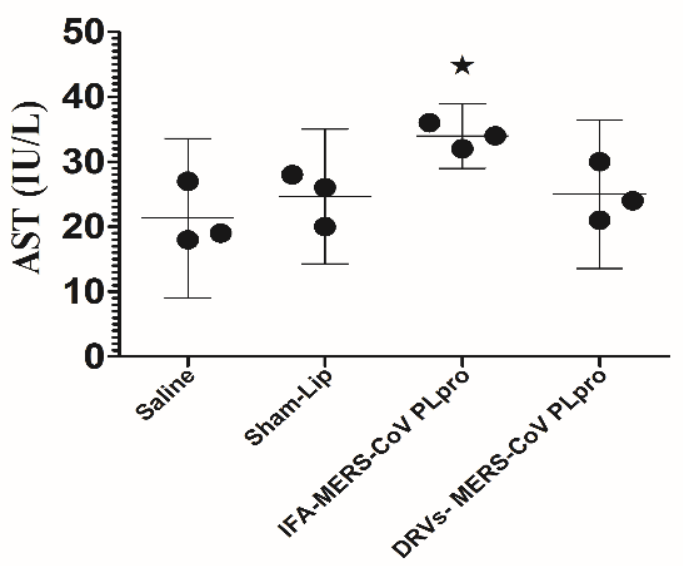

C

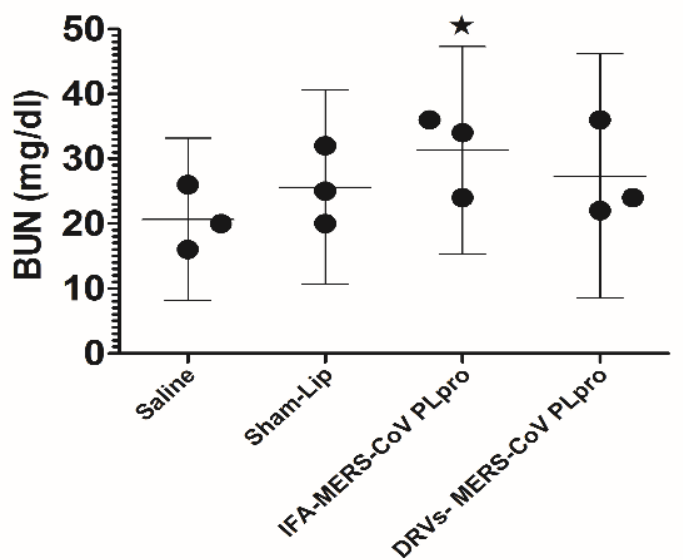

B

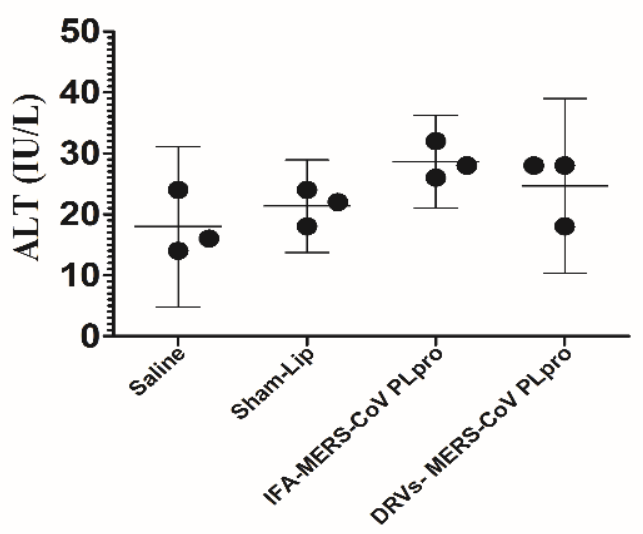

D

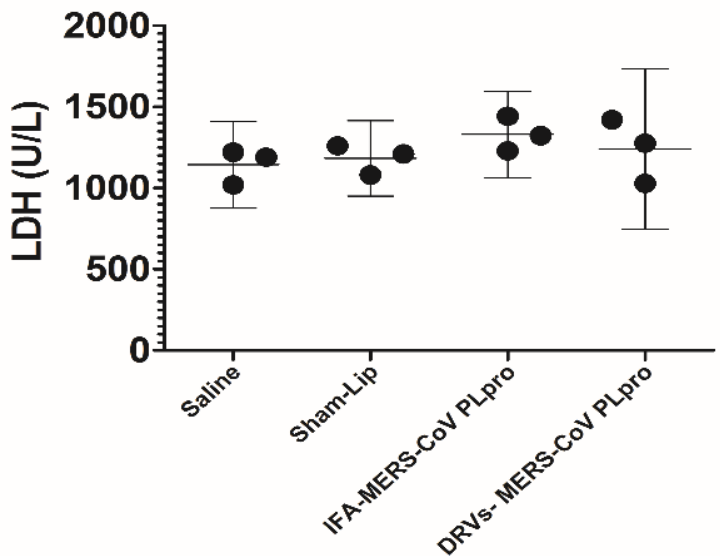

Figure 2. Safety assessment of vaccine formulations. (A) AST level in the control and immunized mice. Saline vs. IFA-MERS-CoV PLpro, ${ }^{*}(p<0.05)$. (B) ALT level in the control and immunized mice. (C) BUN level in the control and immunized mice. Saline vs. IFA-MERS-CoV PLpro, ${ }^{*}(p<0.05)$. (D) LDH level in the control and immunized mice. The data are represented as the mean $\pm \mathrm{SD}$ of three independent values.

\subsection{Immunization with DRVs-MERS-CoV PLpro Induced Higher Antigen-Specific Antibody} Secretion and the Greater Ratio of IgG2a/IgG1

The production of antigen-specific IgG in the sera of mice immunized with IFAMERS-CoV PLpro or DRVs-MERS-CoV PLpro was determined in the sera of mice. A higher level of antibody was found in the sera of mice immunized with DRVs-MERS-CoV PLpro as compared to those immunized with IFA-MERS-CoV PLpro (Figure 3A). This indicates that the immunization with DRVs-MERS-CoV PLpro effectively stimulated the antibody production and humoral immune response. The impact of the immunization with IFA-MERS-CoV PLpro or DRVs-MERS-CoV PLpro was assessed by evaluating the antigenspecific IgG1 and IgG2a isotypes. The results demonstrated that there were comparable levels of IgG1 in the sera of mice immunized with IFA-MERS-CoV PLpro or DRVs-MERSCoV PLpro (Figure 3B). On the other hand, the titer of IgG2a was found to be greater in the sera of mice immunized with DRVs-MERS-CoV PLpro, particularly on day 26 postimmunization (Figure $3 C)(p<0.05)$. The ratio of IgG2a/IgG1 was found to be greater in mice immunized with DRVs-MERS-CoV PLpro as compared to that in mice immunized with IFA-MERS-CoV PLpro (Figure 3D) $(p<0.05)$. 
A

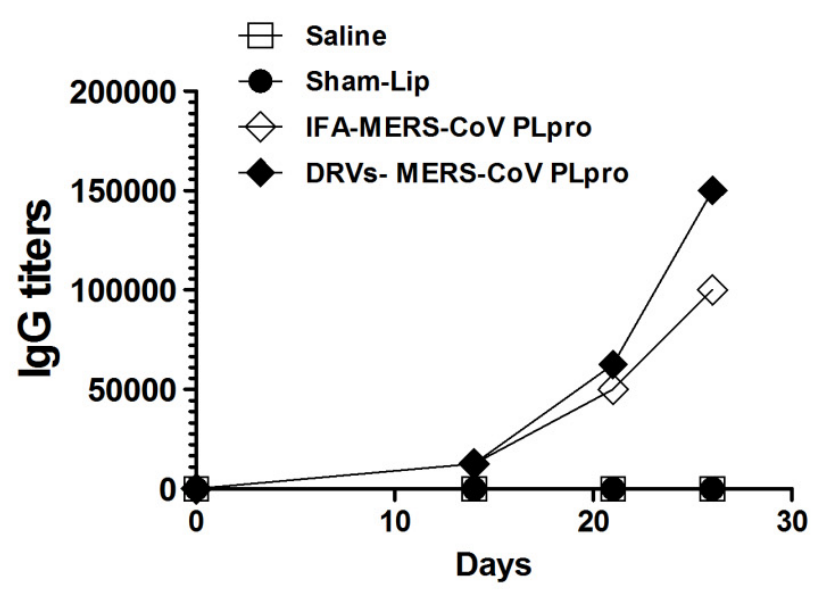

C

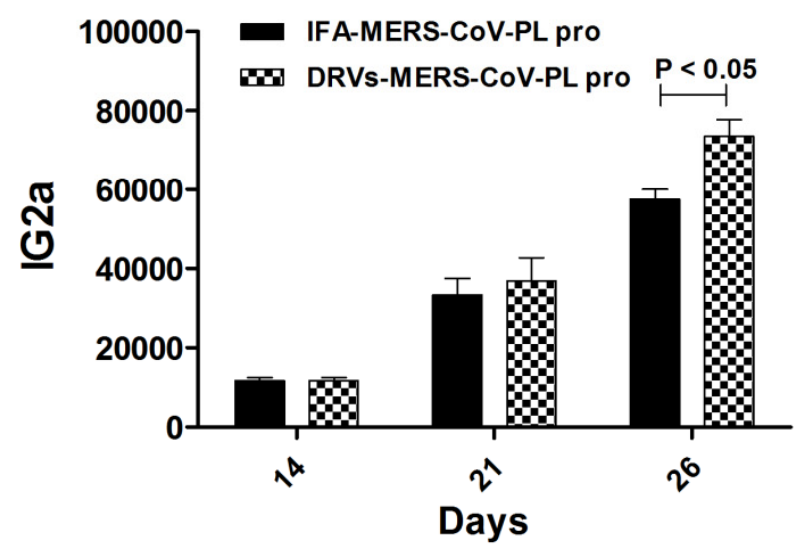

B

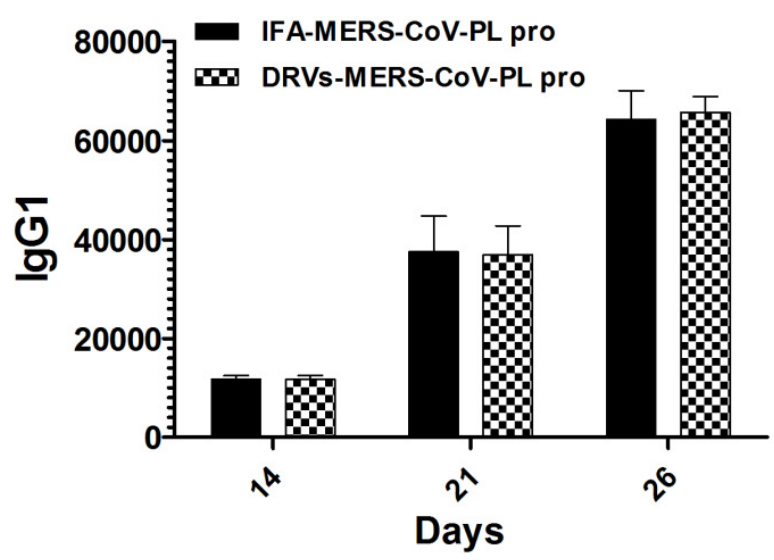

D

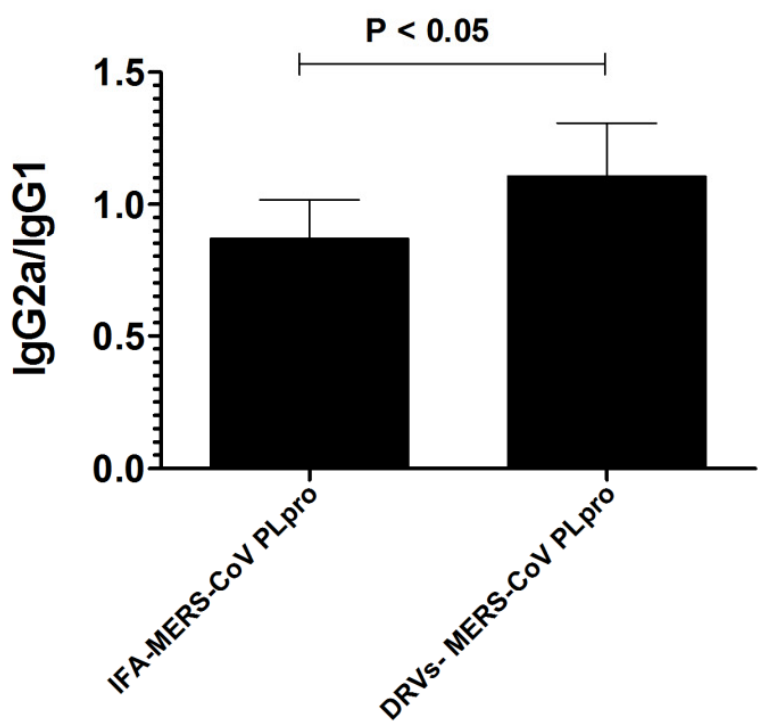

Figure 3. The level of (A) total IgG titer, (B) IgG1, (C) IgG2a, and (D) ratio of IgG2a/IgG1 on day 26 in mice immunized with IFA-MERS-CoV-PL pro or Lip-MERS-CoV-PL pro. The data are represented as the mean $\pm 95 \% \mathrm{CI}$ of three independent values.

\subsection{Immunization with DRVs-MERS-CoV PLpro Induced Greater Proliferation of} Antigen-Specific Lymphocytes

We analyzed the proliferation of antigen-specific lymphocytes in mice immunized with IFA-MERS-CoV PLpro or DRVs-MERS-CoV PLpro. A significantly higher proliferation of antigen-specific lymphocytes was observed in mice immunized with DRVs-MERS-CoV PLpro as compared to those immunized with IFA-MERS-CoV PLpro (Figure 4) $(p<0.01)$. Mice immunized with Sham-lip did not show any increase in lymphocyte proliferation as compared to the saline-treated mice.

3.5. The Splenocytes from the Mice Immunized with DRVs-MERS-CoV PLpro Secreted Higher Level of IFN- $\gamma$

The effectiveness of IFA-MERS-CoV PLpro or DRVs-MERS-CoV PLpro immunization was examined on the secretion of IFN $-\gamma$ and IL- 4 by the splenocytes from the immunized mice. The IFN- $\gamma$ level was found to be $142 \pm 28 \mathrm{pg} / \mathrm{mL}$ in the supernatant of spleno- 
cytes from mice immunized with DRVs-MERS-CoV PLpro, whereas mice immunized with IFA-MERS-CoV PLpro had an IFN- $\gamma$ level of $56 \pm 24$ pg/mL (Figure 5A) $(p<0.01)$. Contrarily, the level of IL-4 was found to be $352 \pm 51 \mathrm{pg} / \mathrm{mL}$ in the supernatant of splenocytes from mice immunized with IFA-MERS-CoV PLpro as compared to an IL-4 level of $376 \pm 66 \mathrm{pg} / \mathrm{mL}$ in mice immunized with DRVs-MERS-CoV PLpro (Figure 5B).

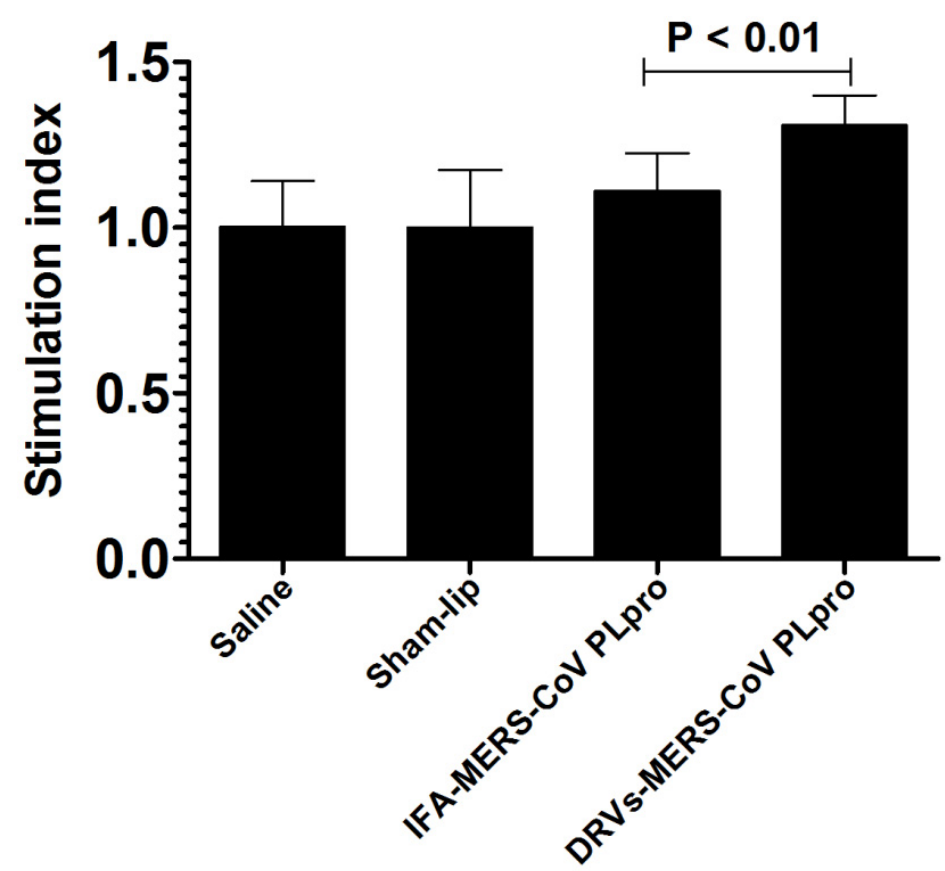

Figure 4. The splenocytes from mice immunized with DRVs-MERS-CoV PL pro showed greater antigen-specific proliferation. The data are represented as the mean $\pm 95 \% \mathrm{CI}$ of the values from three mice.

A

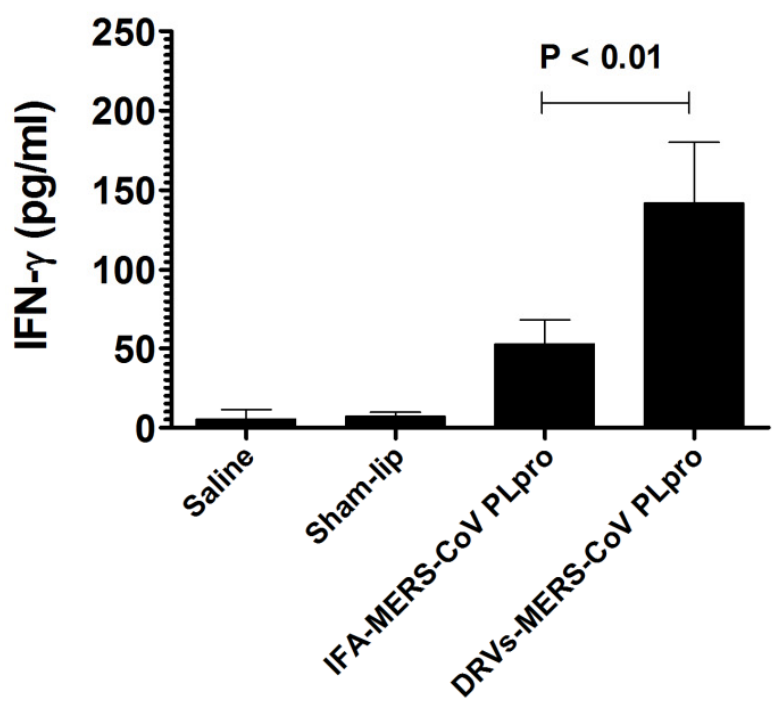

B

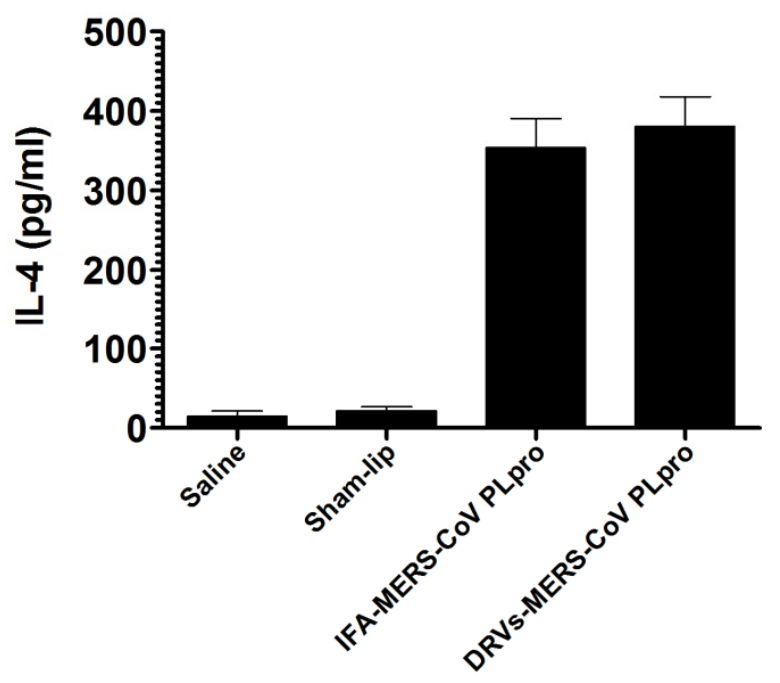

Figure 5. The splenocytes from mice immunized with DRVs-MERS-CoV PLpro produced higher levels of (A) IFN- $\gamma$ and (B) IL-4. The data are represented as the mean \pm SD of the values from three mice. 


\section{Discussion}

Various nanoparticles, including the Virosomes, Poly(lactide-co-glycolide) nanoparticles, liposomes, and nano-emulsions have been implicated as promising vaccine carriers and immunoadjuvants [26-30]. The outcomes of the present study demonstrated that the entrapment of MERS-CoV-PLpro in DRVs induced greater antigen-specific immune responses in mice. The greater immunoadjuvant potential of liposomes is attributed to the fact that they act as an antigen depot and release the entrapped antigen for a longer duration [31]. Liposome-entrapped antigens are easily taken up by the antigen-presenting cells, including dendritic cells [31,32]. We previously showed that the delivery of HIV gp120 protein entrapped in escherisomes induced superior cell-mediated and humoral immune responses [22].

In recent years, the clinical use of neutralizing antibodies has been very promising in the prophylactic and therapeutic prevention of human coronavirus infections [33]. Some MERS-CoV-specific humanized neutralizing antibodies, including MERS-27 m336, MERS-GD27, and 4C2h hMS-1 have effectively shown their antiviral potential in animal models $[34,35]$. Hoecke et. al. demonstrated that the influenza virus membrane protein M2-specific IgG2a imparted greater protection against influenza virus as compared to antigen-specific IgG1 [36]. In the present study, we have used MERS PLpro as an antigen and incorporated it in DPPC-liposomes. DRVs were prepared from DPPC liposomes in order to increase the entrapment efficiency of the antigen. MERS-CoV evades the innate immune response of the host through its action as an antagonist of IFN- $\beta$ and NF-kB [37]. The findings of the current study demonstrated that the immunization with DRVs-MERSCoV PLpro not only induced the higher secretion of antigen-specific IgG but also switched IgG1 to IgG2a subtype. IgG2a has been shown to contribute to the proliferation of antigenspecific T cells [38]. This is also supported by the results of the present study that the splenocytes from mice immunized with DRVs-MERS-CoV PLpro demonstrated higher proliferation in response to MERS-CoV PLpro stimulation. The neutralization ability of IgG2a is reported to be higher as compared to IgG1 [39]. Therefore, the stronger IgG2a response may play an important role in the clearance of the virus from the host.

Splenocytes from mice immunized with DRVs-MERS-CoV PLpro produced the highest amount of IFN- $\gamma$. The higher levels of IFN- $\gamma$ against MERS-CoV have been associated with the status of antiviral immune response in infected patients [40]. IFN- $\gamma$ plays an important role in the activation of macrophages and NK cells through its effect on the JAK-STAT signaling pathway [41]. Moreover, IFN- $\gamma$ also promotes antigen presentation by MHC class I molecules [42]. On the other hand, MERS-CoV evades the immune response by downregulating the gene expression of the molecules associated with antigen presentation [43] The results of the present study showed that immunization with DRVs-MERS-CoV PLpro induced a higher secretion of IFN- $\gamma$ that induced an antiviral immune response in an immunized person. However, the secretion of IL-4 was found to be comparable in mice immunized with IFA-MERS-CoV-PL pro and DRVs-MERS-CoV-PL pro. IL-4 secretion directs the immune cells to favor a Th2-type immune response, whereas IFN- $\gamma$ favors a Th1-type immune response. Earlier studies showed that a bacterial antigen emulsified with IFA predominantly induced the production of IL-4, IL-5, and IgG1 that favored a Th2-type immune response [44]. However, immunization with an antigen entrapped in DPPC-liposomes has been shown to induce a Th1-type immune response [45].

In conclusion, the results of the present study demonstrated that the vaccine formulation of DRVs-MERS-CoV PLpro is safe and did not induce any remarkable toxicity in mice. Moreover, mice immunized with DRVs-MERS-CoV PLpro showed higher levels of antigen-specific IgG and the switching of IgG1 to IgG2a. Interestingly, splenocytes from mice immunized with DRVs-MERS-CoV PLpro produced significantly higher levels of IFN- $\gamma$ that contributed to cell-mediated immunity. Importantly, splenocytes from mice immunized with DRVs-MERS-CoV PLpro exhibited higher proliferation in response to antigen stimulation. Thus, the vaccination with DRVs-MERS-CoV PLpro may prove to be a promising prophylactic strategy in the prevention of MERS-CoV infection. However, the 
limitation of the present study is that it does not include the experiments showing prophylactic efficacy of the vaccine formulation against MERS-CoV infection in an animal model.

Author Contributions: Conceptualization, M.A.K. and A.M.; Funding acquisition, M.A.K., A.M., M.A.A., A.M.A. and B.Y.A.; Investigation, M.A.K., A.M. and A.K.; Methodology, M.A.K., A.M., M.A.A., A.M.A., B.Y.A. and A.K.; Project administration, M.A.A. and O.A.R.; Supervision, M.A.K., O.A.R. and A.K.; Writing—original draft, M.A.K. and A.M.; Writing—review and editing, A.K., B.Y.A. and A.M.A. All authors have read and agreed to the published version of the manuscript.

Funding: This work is supported by the grant \# 5575-cams1-2019-2-2-I from the Deanship of Scientific Research, Qassim University to Masood A. Khan.

Institutional Review Board Statement: All experiments were performed according to the regulations of the animal ethics committee of the College of Applied Medical Sciences, Qassim University. (Approval Code: 5575-cams1-2019-2-2-I. Approval Date: 17 December 2019).

Informed Consent Statement: Not applicable.

Data Availability Statement: All relevant data have been provided within the manuscript.

Acknowledgments: The authors gratefully acknowledge the Deanship of Scientific Research, Qassim University, for the financial support of this research study under the Interdisciplinary Grant (No. 5575-cams1-2019-2-2-I) during the 2019 academic year.

Conflicts of Interest: The authors declare no conflict of interest.

Sample Availability: Not available.

\section{References}

1. de Wit, E.; van Doremalen, N.; Falzarano, D.; Munster, V.J. SARS and MERS: Recent insights into emerging coronaviruses. Nat. Rev. Microbiol. 2016, 14, 523-534. [CrossRef] [PubMed]

2. WHO. List of Blueprint Priority Diseases. 2018. Available online: http://www.who.int/blueprint/priority-diseases/en/ (accessed on 6 February 2018).

3. Faridi, U. Middle East respiratory syndrome coronavirus (MERS-CoV): Impact on Saudi Arabia, 2015. Saudi J. Biol. Sci. 2018, 25, 1402-1405. [CrossRef] [PubMed]

4. Alshukairi, A.N.; Zheng, J.; Zhao, J.; Nehdi, A.; Baharoon, S.A.; Layqah, L.; Bokhari, A.; Al Johani, S.M.; Samman, N.; Boudjelal, M.; et al. High Prevalence of MERS-CoV Infection in Camel Workers in Saudi Arabia. mBio 2018, 9, e01985-18. [CrossRef]

5. Alshammari, M.; Reynolds, K.A.; Verhougstraete, M.; O’Rourke, M.K. Comparison of Perceived and Observed Hand Hygiene Compliance in Healthcare Workers in MERS-CoV Endemic Regions. Healthcare 2018, 6, 122. [CrossRef] [PubMed]

6. Shokri, S.; Mahmoudvand, S.; Taherkhani, R.; Farshadpour, F. Modulation of the immune response by Middle East respiratory syndrome coronavirus. J. Cell. Physiol. 2019, 234, 2143-2151. [CrossRef]

7. Mubarak, A.; Alturaiki, W.; Hemida, M.G. Middle East Respiratory Syndrome Coronavirus (MERS-CoV): Infection, Immunological Response, and Vaccine Development. J. Immunol. Res. 2019, 2019, 6491738. [CrossRef]

8. Du, L.; Tai, W.; Zhou, Y.; Jiang, S. Vaccines for the prevention against the threat of MERS-CoV. Expert Rev. Vaccines 2016, 15, 1123-1134. [CrossRef]

9. Coleman, C.M.; Liu, Y.V.; Mu, H.; Taylor, J.K.; Massare, M.; Flyer, D.C.; Smith, G.E.; Frieman, M.B. Purified coronavirus spike protein nanoparticles induce coronavirus neutralizing antibodies in mice. Vaccine 2014, 32, 3169-3174. [CrossRef]

10. Muthumani, K.; Falzarano, D.; Reuschel, E.L.; Tingey, C.; Flingai, S.; Villarreal, D.O.; Wise, M.; Patel, A.; Izmirly, A.; Aljuaid, A.; et al. A synthetic consensus anti-spike protein DNA vaccine induces protective immunity against Middle East respiratory syndrome coronavirus in nonhuman primates. Sci. Transl. Med. 2015, 7, 301ra132. [CrossRef]

11. Ma, C.; Li, Y.; Wang, L.; Zhao, G.; Tao, X.; Tseng, C.T.; Zhou, Y.; Du, L.; Jiang, S. Intranasal vaccination with recombinant receptor-binding domain of MERS-CoV spike protein induces much stronger local mucosal immune response than subcutaneous immunization: Implication for designing novel mucosal MERS vaccines. Vaccine 2014, 32, 2100-2108. [CrossRef] [PubMed]

12. Park, B.K.; Maharjan, S.; Lee, S.I.; Kim, J.; Bae, J.Y.; Park, M.S.; Kwon, H.J. Generation and characterization of a monoclonal antibody against MERS-CoV targeting the spike protein using a synthetic peptide epitope-CpG-DNA-liposome complex. $B M B$ Rep. 2019, 52, 397-402. [CrossRef]

13. Khan, M.A. Targeted Drug Delivery Using Tuftsin-bearing Liposomes: Implications in the Treatment of Infectious Diseases and Tumors. Curr. Drug Targets 2021, 22, 770-778. [CrossRef]

14. Khan, M.A.; Khan, A. Role of NKT Cells during Viral Infection and the Development of NKT Cell-Based Nanovaccines. Vaccines 2021, 9, 949. [CrossRef] 
15. Chan, J.F.; Yao, Y.; Yeung, M.L.; Deng, W.; Bao, L.; Jia, L.; Li, F.; Xiao, C.; Gao, H.; Yu, P.; et al. Treatment with Lopinavir/Ritonavir or Interferon- $\beta 1 \mathrm{~b}$ Improves Outcome of MERS-CoV Infection in a Nonhuman Primate Model of Common Marmoset. J. Infect. Dis. 2015, 212, 1904-1913. [CrossRef]

16. Du, L.; Zhao, G.; Yang, Y.; Qiu, H.; Wang, L.; Kou, Z.; Tao, X.; Yu, H.; Sun, S.; Tseng, C.T.; et al. A conformation-dependent neutralizing monoclonal antibody specifically targeting receptor-binding domain in Middle East respiratory syndrome coronavirus spike protein. J. Virol. 2014, 88, 7045-7053. [CrossRef]

17. Chen, Z.; Wang, Y.; Ratia, K.; Mesecar, A.D.; Wilkinson, K.D.; Baker, S.C. Proteolytic processing and deubiquitinating activity of papain-like proteases of human coronavirus NL63. J. Virol. 2007, 81, 6007-6018. [CrossRef]

18. Yang, X.; Chen, X.; Bian, G.; Tu, J.; Xing, Y.; Wang, Y.; Chen, Z. Proteolytic processing, deubiquitinase and interferon antagonist activities of Middle East respiratory syndrome coronavirus papain-like protease. J. Gen. Virol. 2014, 95, 614-626. [CrossRef]

19. Zhu, W.; Shyr, Z.; Lo, D.C.; Zheng, W. Viral Proteases as Targets for Coronavirus Disease 2019 Drug Development. J. Pharm. Exp. Ther. 2021, 378, 166-172. [CrossRef] [PubMed]

20. Malik, A.; Alsenaidy, M.A. MERS-CoV papain-like protease (PL ${ }^{\text {pro }}$ ): Expression, purification and spectroscopic/thermodynamic characterization. 3 Biotech 2017, 7, 100. [CrossRef] [PubMed]

21. Khan, M.A.; Aljarbou, A.N.; Aldebasi, Y.H.; Alorainy, M.S.; Rahmani, A.H.; Younus, H.; Khan, A. Liposomal formulation of glycosphingolipids from Sphingomonas paucimobilis induces antitumor immunity in mice. J. Drug Target. 2018, 26, 709-719. [CrossRef] [PubMed]

22. Allemailem, K.S.; Alnuqaydan, A.M.; Almatroudi, A.; Alrumaihi, F.; Aljaghwani, A.; Khalilullah, H.; Younus, H.; Khan, A.; Khan, M.A. Safety and Therapeutic Efficacy of Thymoquinone-Loaded Liposomes against Drug-Sensitive and Drug-Resistant Acinetobacter baumannii. Pharmaceutics 2021, 13, 677. [CrossRef]

23. Ahmad, N.; Khan, M.A.; Owais, M. Liposome mediated antigen delivery leads to induction of CD8+ T lymphocytes and antibody responses against the V3 loop region of HIV gp120. Cell. Immunol. 2001, 210, 49-55. [CrossRef]

24. Khan, M.A.; Aljarbou, A.N.; Aldebasi, Y.H.; Alorainy, M.S.; Khan, A. Combination of glycosphingosomes and liposomal doxorubicin shows increased activity against dimethyl- $\alpha$-benzanthracene-induced fibrosarcoma in mice. Int. J. Nanomed. 2015, 10, 6331-6338. [CrossRef]

25. Syed, F.M.; Khan, M.A.; Nasti, T.H.; Ahmad, N.; Mohammad, O. Antigen entrapped in the escheriosomes leads to the generation of CD4 (+) helper and CD8 (+) cytotoxic T cell response. Vaccine 2003, 21, 2383-2393. [CrossRef]

26. Smith, D.M.; Simon, J.K.; Baker, J.R., Jr. Applications of nanotechnology for immunology. Nat. Rev. Immunol. 2013, 13, 592-605. [CrossRef] [PubMed]

27. Dhakal, S.; Renukaradhya, G.J. Nanoparticle-based vaccine development and evaluation against viral infections in pigs. Vet. Res. 2019, 50, 90. [CrossRef]

28. Brunel, F.; Darbouret, A.; Ronco, J. Cationic lipid DC-Chol induces an improved and balanced immunity able to overcome the unresponsiveness to the hepatitis B vaccine. Vaccine 1999, 17, 2192-2203. [CrossRef]

29. Blom, R.A.; Erni, S.T.; Krempaská, K.; Schaerer, O.; van Dijk, R.M.; Amacker, M.; Moser, C.; Hall, S.R.; von Garnier, C.; Blank, F. A Triple Co-Culture Model of the Human Respiratory Tract to Study Immune-Modulatory Effects of Liposomes and Virosomes. PLoS ONE 2016, 11, e0163539. [CrossRef] [PubMed]

30. Klinguer, C.; Beck, A.; De-Lys, P.; Bussat, M.C.; Blaecke, A.; Derouet, F.; Bonnefoy, J.Y.; Nguyen, T.N.; Corvaïa, N.; Velin, D. Lipophilic quaternary ammonium salt acts as a mucosal adjuvant when co-administered by the nasal route with vaccine antigens. Vaccine 2001, 19, 4236-4244. [CrossRef]

31. Bernasconi, V.; Norling, K.; Bally, M.; Höök, F.; Lycke, N.Y. Mucosal Vaccine Development Based on Liposome Technology J. Immunol. Res. 2016, 2016, 5482087. [CrossRef] [PubMed]

32. Tanaka, Y.; Taneichi, M.; Kasai, M.; Kakiuchi, T.; Uchida, T. Liposome-coupled antigens are internalized by antigen-presenting cells via pinocytosis and cross-presented to CD8 T cells. PLoS ONE 2010, 5, e15225. [CrossRef]

33. Jiang, S.; Hillyer, C.; Du, L. Neutralizing Antibodies against SARS-CoV-2 and Other Human Coronaviruses. Trends Immunol. 2020, 41, 355-359. [CrossRef]

34. Du, L. MERS-CoV spike protein: A key target for antivirals. Expert Opin. Ther. Targets 2017, 21, 131-143. [CrossRef] [PubMed]

35. Zhou, Y. Advances in MERS-CoV vaccines and therapeutics based on the receptor-binding domain. Viruses 2019, 11, 60. [CrossRef]

36. Van den Hoecke, S.; Ehrhardt, K.; Kolpe, A.; El Bakkouri, K.; Deng, L.; Grootaert, H.; Schoonooghe, S.; Smet, A.; Bentahir, M.; Roose, K.; et al. Hierarchical and Redundant Roles of Activating Fc $\gamma$ Rs in Protection against Influenza Disease by M2e-Specific IgG1 and IgG2a Antibodies. J. Virol. 2017, 91, e02500-16. [CrossRef]

37. Mielech, A.M.; Kilianski, A.; Baez-Santos, Y.M.; Mesecar, A.D.; Baker, S.C. MERS-CoV papain-like protease has deISGylating and deubiquitinating activities. Virology 2014, 450-451, 64-70. [CrossRef]

38. Getahun, A.; Dahlström, J.; Wernersson, S.; Heyman, B. IgG2a-mediated enhancement of antibody and T cell responses and its relation to inhibitory and activating Fc gamma receptors. J. Immunol. 2004, 172, 5269-5276. [CrossRef] [PubMed]

39. Nimmerjahn, F.; Ravetch, J.V. Divergent immunoglobulin g subclass activity through selective Fc receptor binding. Science 2005, 310, 1510-1512. [CrossRef]

40. Yao, Z.; Zheng, Z.; Wu, K.; Junhua, Z. Immune environment modulation in pneumonia patients caused by coronavirus: SARS-CoV, MERS-CoV and SARS-CoV-2. Aging 2020, 12, 7639-7651. [CrossRef] [PubMed] 
41. Mahallawi, W.H.; Khabour, O.F.; Zhang, Q.; Makhdoum, H.M.; Suliman, B.A. MERS-CoV infection in humans is associated with a pro-inflammatory Th1 and Th17 cytokine profile. Cytokine 2018, 104, 8-13. [CrossRef]

42. Zhou, F. Molecular mechanisms of IFN-gamma to up-regulate MHC class I antigen processing and presentation. Int. Rev. Immunol. 2009, 28, 239-260. [CrossRef] [PubMed]

43. Menachery, V.D.; Schäfer, A.; Burnum-Johnson, K.E.; Mitchell, H.D.; Eisfeld, A.J.; Walters, K.B.; Nicora, C.D.; Purvine, S.O.; Casey, C.P.; Monroe, M.E.; et al. MERS-CoV and H5N1 influenza virus antagonize antigen presentation by altering the epigenetic landscape. Proc. Natl. Acad. Sci. USA 2018, 115, E1012-E1021. [CrossRef] [PubMed]

44. Chu, R.S.; Targoni, O.S.; Krieg, A.M.; Lehmann, P.V.; Harding, C.V. CpG oligodeoxynucleotides act as adjuvants that switch on T helper 1 (Th1) immunity. J. Exp. Med. 1997, 186, 1623-1631. [CrossRef]

45. Badiee, A.; Jaafari, M.R.; Khamesipour, A.; Samiei, A.; Soroush, D.; Kheiri, M.T.; Barkhordari, F.; McMaster, W.R.; Mahboudi, F. Enhancement of immune response and protection in BALB/c mice immunized with liposomal recombinant major surface glycoprotein of Leishmania (rgp63): The role of bilayer composition. Colloids Surf. B Biointerfaces 2009, 74, 37-44. [CrossRef] [PubMed] 